\title{
A feminização do magistério: o lugar da mulher como professora no Triângulo Mineiro e Alto Paranaíba
}

\author{
The feminization of the magistry: the place of women \\ as a teacher in the Triângulo Mineiro e Alto Paranaíba \\ La feminización de la docencia: el lugar de la mujer como \\ profesora en el Triángulo Mineiro y Alto Paranaíba \\ MiCHELLE CASTRO LIMA ${ }^{a}$
}

\section{Resumo}

A docência no ensino primário difundida como um "dom" feminino foi um marco na feminização do magistério. Este estudo bibliográfico buscou analisar a formação de professoras da Escola Normal e do Magistério e a relação entre a feminização e o exercício do magistério a partir da análise de 15 dissertações e 5 teses que abordam a formação de professores para atuar na alfabetização no Triângulo Mineiro e Alto Paranaíba, no período de 1946 a 1979. Para desenvolvimento da pesquisa utilizamos como aporte teórico a Nova História Cultural. Identificamos que a escolha pelo magistério não foi motivada por um desejo ou o sonho pela profissão e que a maioria dos alunos eram mulheres. As professoras alfabetizadoras eram direcionadas para esta profissão em decorrência de elementos relacionados com o desejo familiar e a imposição moral vigente, a partir dos valores cristãos disseminados nas Igrejas. Os homens afastaram-se do magistério primário devido à desvalorização da área e aos baixos salários, bem como pela influência da Igreja Católica, que apresentava impedimentos morais para a atuação masculina no ensino primário, enquanto enaltecia o papel da mulher nessa função com base na ideia de vocação e de extensão da maternidade. Neste contexto, era necessário formar professoras para instruir no ensino primário. Esse movimento culminou na feminização do setor.

Palavras-chave: Formação de Professoras. Docência. História. Igreja.

\footnotetext{
a Instituto Federal Goiano Campus Morrinhos, Morrinhos, GO, Brasil. Doutora em Educação, e-mail: michelle.lima@ifgoiano.edu.br
} 


\begin{abstract}
The action of teaching understands a "gift" in primary education was a milestone in the feminization of teaching. This bibliographic study sought to analyze the teacher's training from Escola Normal and Vocational course in Teaching (High School) and the relationship between feminization and the exercise of teaching. This study wore wrote from the analysis of 15 dissertations and 5 theses that address the training of teachers to work on literacy in the "Triangulo Mineiro" and "Alto Paranaíba", from 1946 to 1979. For the development of the research, we used the New Cultural History as a theoretical contribution. We identified that the choice for teaching was not motivated by a desire or dream for the profession and that the majority of students were women. The literacy teachers were directed to this profession due to family desire and a current moral imposition, based on the Christian values disseminated in the Churches. The men moved away from primary teaching due to the devaluation of the area and low salaries, as well as the influence of the Catholic Church, which presented moral impediments to male performance in primary education while extolling the role of women in this function based on the idea vocation and extension of motherhood. In this context, it was necessary to train teachers, women, to instruct in primary education. This movement culminated in the feminization of the sector.
\end{abstract}

Keywords: Teacher Training. Teaching. Story. Church.

\title{
Resumen
}

La enseñanza en la educación primaria difundida como un "don" femenino fue un hito en la feminización de la docencia. Este estudio bibliográfico buscó analizar la formación del profesorado de la Escola Normal y do Ensino [Magisterio] y la relación entre la feminización y el ejercicio de la docencia a partir del análisis de 15 disertaciones y 5 tesis que abordan la formación del profesorado para trabajar la alfabetización en el Triángulo Mineiro y Alto Paranaíba, de 1946 a 1979. Para el desarrollo de la investigación utilizamos como aporte teórico la Nueva Historia Cultural. Identificamos que la elección de la docencia no fue motivada por un deseo o sueño por la profesión y que la mayoría de los estudiantes eran mujeres. Los alfabetizadores se orientaron a esta profesión por elementos relacionados con el deseo familiar y la imposición moral actual, basada en los valores cristianos difundidos en las Iglesias. Los hombres se retiraron de la enseñanza primaria debido a la devaluación de la zona y los bajos salarios, así como la influencia de la Iglesia Católica, que presentó impedimentos morales para el desempeño masculino en la educación primaria, al tiempo que ensalzaba el papel de la mujer en esta función a partir de la idea de vocación y extensión de la maternidad. En este contexto, fue necesario capacitar a los docentes para instruir en la educación primaria. Este movimiento culminó con la feminización del sector.

Palabras clave: Formación de profesores. Enseñando. Historia. Iglesia. 
Este artigo trata da feminização do magistério do antigo ensino primário, atualmente denominado primeira fase do Ensino Fundamental, com base em pesquisa bibliográfica sobre a formação de professores no Triângulo Mineiro e Alto Paranaíba, regiões do estado de Minas Gerais, no período de 1946 a $1979{ }^{1}$. Buscamos, nos menores indícios, analisar a formação de professoras na Escola Normal e na de Magistério e a relação entre a feminização e o exercício do magistério. Nossa hipótese, nesta pesquisa exploratória e bibliográfica, é de que a atuação de apenas mulheres como professoras nas salas de alfabetização é resultado da concepção construída socialmente de que a docência do ensino primário é um dom feminino.

Foram selecionadas e analisadas 5 teses e 15 dissertações que abordam a história da alfabetização no Triângulo Mineiro e Alto Paranaíba no período de 1946 a 1979. Para tal, realizamos uma pesquisa nos bancos de teses e dissertações a fim de identificar os trabalhos de pós-graduação que abordem a temática história da formação das alfabetizadoras naquelas duas regiões de Minas Gerais.

A seleção das dissertações e teses utilizadas nesta pesquisa ocorreu a partir da análise inicial dos resumos dos trabalhos encontrados que faziam parte do tema e do recorte temporal estabelecido. Após esta primeira seleção, analisamos os textos completos. Utilizamos como aporte teórico a Nova História Cultural, a qual abre novas possibilidades de pesquisa. Essa opção se deve a que "A base filosófica da Nova História é a ideia de que a realidade é social ou culturalmente constituída" (BURKE, 1992, p. 11), o que corrobora nossa convicção.

Utilizamos como fonte e objeto as teses e dissertações publicadas nos dois maiores bancos de teses e dissertações do Brasil - Banco de teses da Coordenação

\footnotetext{
${ }^{1}$ A delimitação do início de pesquisa em 1946 ocorreu devido à promulgação do Decreto-Lei no 8.530, de 02 de janeiro de 1946 que regulamenta o Ensino Normal no Brasil. Esse decreto é importante quando falamos de formação de professores, pois ele irá dar as novas diretrizes para formação do professor do ensino primário no curso normal. Encerraremos a pesquisa no ano de 1979, pois nesse período há uma mudança no processo de alfabetização e de formação do alfabetizador devido à publicação em português do livro Psicogênese da Língua Escrita, dos autores Ferreiro e Teberosky (1991), que apresenta outros conceitos sobre o processo de alfabetização e, com isso, irá influenciar a prática e a formação das professoras alfabetizadoras

a Instituto Federal Goiano Campus Morrinhos, Morrinhos, GO, Brasil. Doutora em Educação, e-mail: michelle.lima@ifgoiano.edu.br
} 
de Aperfeiçoamento de Pessoal de Nível Superior (CAPES) e Biblioteca Digital Brasileira de Teses e Dissertações / Instituto Brasileiro de Informação em Ciência e Tecnologia (IBICT). Inicialmente, estabelecemos como filtro para a pesquisa nos bancos de teses e dissertações os seguintes termos: formação de professoras primárias, formação de professores primários, formação de alfabetizadoras, formação de alfabetizadores, história de alfabetizadores de Minas Gerais, história da alfabetização de Minas Gerais, alfabetizadoras em Minas Gerais, práticas de alfabetizadoras em Minas Gerais e alfabetização e formação em Minas Gerais.

Inicialmente planejamos buscar os trabalhos nas sete microrregiões do Triângulo Mineiro e Alto Paranaíba, porém, após essa busca, identificamos que não há trabalhos de mestrado ou doutorado que se refiram à história da formação de alfabetizadores em algumas delas. Dessa forma, decidimos ampliar a pesquisa no banco de teses e dissertações, sendo inserida, como filtro, a expressão "Escola Normal”. A partir de então, foi possível encontrar mais trabalhos sobre Escola Normal que abordam a formação do professor alfabetizador ou a temática "quem são as alfabetizadoras formadas nesses locais".

Foram então localizados 427 trabalhos, dos quais selecionamos 20 que tratam, de alguma forma, da formação do professor alfabetizador no Triângulo Mineiro e Alto Paranaíba. Entretanto, eles não se restringem à formação de alfabetizadores, mas percorrem as seguintes temáticas: livros didáticos, Grupos Escolares, Escola Normal e história das disciplinas ${ }^{2}$ específicas para alfabetização, mas sempre abordam, em algum aspecto, a formação do professor na escola Normal ou no Magistério. Além disso, seu recorte temporal atinge parte ou a totalidade do período entre 1946 e 1979. No quadro 1 estão relacionados os 20 trabalhos selecionados.

\section{Quadro 1 - Teses e Dissertações Selecionadas}

\footnotetext{
${ }^{2}$ Foram encontrados 2 trabalhos que tratam da história da disciplina História da Educação, porém um deles não aborda a temática "formação de alfabetizadores" e, por isso, não será utilizado.
} 


\begin{tabular}{|c|c|c|c|}
\hline 01 & A Educação feminina do Projeto Siqueirano: 1939-1973 & $\begin{array}{l}\text { Gislene Taveira de Almeida } \\
\text { Neves }\end{array}$ & M \\
\hline 02 & $\begin{array}{l}\text { A Escola Normal de Patos de Minas: 1932-1972. Na } \\
\text { encruzilhada entre o novo e o velho. }\end{array}$ & Maria Terezinha de Brito & M \\
\hline 03 & $\begin{array}{l}\text { Colégio Imaculada Conceição: a história do curso Normal } \\
\text { (Tupaciguara-MG, 1961-1977). }\end{array}$ & Izabel Rozetti & M \\
\hline 04 & $\begin{array}{l}\text { Colégio Normal Nossa Senhora do Patrocínio: um } \\
\text { instrumento de educação feminina na Zona do Alto } \\
\text { Paranaíba em Minas Gerais (1928-1950). }\end{array}$ & Hedmar de Oliveira Ferreira & $\mathrm{D}$ \\
\hline 05 & Escola rural e alfabetização: Uberlândia 1936 a 1946 & Cristiane Angélica Ribeiro & M \\
\hline 06 & $\begin{array}{l}\text { História da alfabetização de Ituiutaba: vivências no Grupo } \\
\text { Escolar Governador Clóvis Salgado-1957-1971 }\end{array}$ & $\begin{array}{l}\text { Tânia Rezende Silvestre } \\
\text { Cunha }\end{array}$ & $\mathrm{D}$ \\
\hline 07 & $\begin{array}{l}\text { História da Escola Rural Santa Tereza (Uberlândia/MG, } \\
1934 \text { a 1953) }\end{array}$ & Tania Cristina da Silveira & M \\
\hline 08 & $\begin{array}{l}\text { História de alfabetizadoras Uberlandenses: modos de } \\
\text { fazer no Grupo Escolar Bom Jesus } 1955 \text { a } 1971\end{array}$ & Michelle Castro Lima & M \\
\hline 09 & $\begin{array}{l}\text { História de Formação de Alfabetizadoras: A disciplina } \\
\text { didática da Linguagem no Magistério } 1971 \text { a } 1985\end{array}$ & Tatiane Batista Macedo & M \\
\hline 10 & $\begin{array}{l}\text { História e Memória da Alfabetização em Canápolis - } \\
\text { MG: Revisitando as Cartilhas Utilizadas no Período } \\
\text { de1933-1971 }\end{array}$ & $\begin{array}{l}\text { Vanessa Ferreira Silva } \\
\text { Arantes }\end{array}$ & M \\
\hline 11 & $\begin{array}{l}\text { História e Memória da Formação Docente em Ituiutaba - } \\
\text { MG }\end{array}$ & $\begin{array}{l}\text { Andréia Demetrio Jorge } \\
\text { Moraes }\end{array}$ & $\mathrm{D}$ \\
\hline 12 & História e Ofício de Alfabetizadoras: Ituiutaba 1931-1961 & $\begin{array}{l}\text { Andréia Demetrio Jorge } \\
\text { Moraes }\end{array}$ & M \\
\hline 13 & Histórias de alfabetizadores: vida, memória e profissão. & Edite da Glória A. Guimarães & M \\
\hline 14 & $\begin{array}{l}\text { Modos de alfabetizar no grupo escolar Clarimundo } \\
\text { Carneiro - } 1963 \text { A } 1973\end{array}$ & Vanessa Lepick & M \\
\hline 15 & $\begin{array}{l}\text { O curso Normal do Colégio Sagrado Coração de Jesus } \\
\text { Araguari - MG (1930-1947) }\end{array}$ & Melina Brasil Silva & M \\
\hline 16 & $\begin{array}{l}\text { O Grupo Escolar Minas Gerais e a Educação Pública } \\
\text { Primária em Uberaba (MG) entre } 1927 \text { e } 1962\end{array}$ & Marilza A. Alberto Assis Souza & M \\
\hline 17 & $\begin{array}{l}\text { Por trás dos Muros Escolares: Luzes e Sombras na } \\
\text { Educação Feminina (Colégio N. Sra. Das Dores - Uberaba } \\
\text { 1940/1966) }\end{array}$ & Geovana Ferreira Melo & $\mathrm{M}$ \\
\hline 18 & $\begin{array}{l}\text { Trilhas e Rastros da Educação Primária: História do Grupo } \\
\text { Escolar Coronel José Teófilo Carneiro, Uberlândia-MG, } \\
\text { 1940-1970 }\end{array}$ & $\begin{array}{l}\text { Geovanna de Lourdes Alves } \\
\text { Ramos }\end{array}$ & $\mathrm{D}$ \\
\hline 19 & $\begin{array}{l}\text { Ser professora na república: modos de pensar, sentir e } \\
\text { agir (1930-1950) }\end{array}$ & Rosa Maria de Sousa Martins & M \\
\hline 20 & $\begin{array}{l}\text { O percurso institucional da disciplina "História da } \\
\text { Educação" em Minas Gerais e o seu ensino na Escola } \\
\text { Normal Oficial de Uberaba (1928 - 1970) }\end{array}$ & $\begin{array}{l}\text { Rosângela Maria Castro } \\
\text { Guimarães }\end{array}$ & $\mathrm{D}$ \\
\hline
\end{tabular}

Fonte: Autoras. Elaborado a partir dos Bancos de Dados de Teses da CAPES e Banco Digital de teses e dissertações IBICT.

Para o desenvolvimento dessas teses e dissertações, os autores utilizaram diferentes fontes e objetos: cinco deles utilizaram documentos, sete, além dos 
documentos, recorreram a entrevistas como técnica e oito empregaram os documentos e as entrevistas na perspectiva da História Oral. Percorremos os trabalhos e, através dos indícios, construímos a história da alfabetização no Triângulo Mineiro e Alto Paranaíba na perspectiva da formação do alfabetizador.

Nesses estudos, identificamos que a maioria dos professores alfabetizadores são do sexo feminino, o que faz toda a diferença para o estudo da formação e trabalho docente, conforme salienta Carvalho (1996). E é nessa perspectiva que estamos trabalhando, já que a educação da mulher foi diferenciada da educação masculina, conforme fica evidente na Lei $\mathrm{n}^{\circ}$ 8.347, de 10 de dezembro de 1945:

Art. 25. Serão observadas, no ensino secundário feminino, as seguintes prescrições especiais:

1. É preferível que a educação secundária das mulheres se faça em estabelecimentos de ensino de exclusiva freqüência feminina.

2. Nos estabelecimentos de ensino secundário freqüentados por homens e mulheres, será a educação destas ministrada, sempre que possível, em classes exclusivamente femininas.

3. Incluir-se-á, na terceira e na quarta série do curso ginasial, a disciplina de economia doméstica.

4. A orientação metodológica dos programas terá em mira a natureza da personalidade feminina e bem assim a missão da mulher no lar. (BRASIL, 1945).

Assim, para realizarmos tal análise, primeiramente se fez necessário retomar aspectos da história da docência primária. Segundo Louro (2000) "[...] a atividade docente, no Brasil, como em muitas outras sociedades, havia sido iniciada por homens - aqui religiosos, especialmente jesuítas, no período compreendido entre 1549 e 1759” (LOURO, 2000, p. 449). A educação feminina, de acordo com a tradição portuguesa, “[...] fora negada sob o pretexto de que conhecimento e sabedoria eram desnecessários e prejudiciais à sua frágil constituição física e intelectual [...].” (ALMEIDA, 1998, p. 33). Sendo assim, no Brasil o magistério foi considerado uma profissão masculina até os anos finais do século XIX. Aos poucos a docência feminina foi ocupando lugar na sociedade, iniciando-se com a instrução de moças de famílias abastadas. Essa instrução, contudo, estava direcionada para a formação de mulheres "prendadas". Verificamos que, "ao longo da história, a educação e a profissionalização femininas têm sido sempre relegadas a um plano secundário” (ALMEIDA, 1998, p.31). 
Os homens afastaram-se do magistério primário devido à desvalorização da área e aos baixos salários, bem como pela influência da Igreja Católica, que apresentava impedimentos morais para a atuação masculina no ensino primário, enquanto enaltecia o papel da mulher nessa função com base na ideia de vocação e de extensão da maternidade. Neste contexto, era necessário formar professoras para instruir no ensino primário. Esse movimento culminou na feminização do setor. Ademais, nota-se que esse processo, que se propagou na república, ganhou gradativamente uma nova textura, já que os ideais republicanos pregavam a instrução da sociedade, bem como a "crença no poder da educação" (ALMEIDA, 1998, p. 66).

\section{A mulher na Educação Brasileira}

Durante um longo período, a mulher foi idealizada como um ser frágil, dócil, nascido para a maternidade e para o lar. Era, então, para isso preparada desde o seu nascimento e, para tais funções bem delimitadas, não precisava de outra formação.

As primeiras iniciativas de instrução feminina foram voltadas para a formação da esposa "perfeita", da mulher/mãe dotada de valores e princípios morais e religiosos. Essa instrução não tinha um cunho de emancipação feminina, mas, acima de tudo, era uma reafirmação de suas atribuições como mãe virtuosa.

Durante muitos anos as mulheres foram mantidas afastadas do saber intelectual, bem como do trabalho digno e remunerado. Segundo Almeida (1998), a instrução poderia trazer-lhes um novo direcionamento. Assim,

[...] a necessidade de instruir-se e educar-se constituía um dos principais anseios para sua libertação e uma forma de alterar um destino imposto pela sociedade moralizadora que se erigia nos padrões de uma época resultante de um acelerado processo de urbanização (ALMEIDA, 1998, p. 33).

A princípio, a educação foi voltada para filhas de famílias ricas. Essas moças deixaram de ser mães de família "ignorantes” para serem mães de família educadas, dentro do princípio da moral cristã. A Lei de 15 de outubro de 1827, a primeira no Brasil que rege sobre o ensino de meninas, diz: “Art. 11. Haverão escolas de 
meninas nas cidades e vilas mais populosas, em que os Presidentes em Conselho, julgarem necessário este estabelecimento” (BRASIL, 1878).

A referida legislação ainda destaca como será a formação das professoras que irão educar essas meninas:

Art. 12. As Mestras, além do declarado no Art. $6^{\circ}$, com exclusão das noções de geometria e limitado a instrução de aritmética só as suas quatro operações, ensinarão também as prendas que servem à economia doméstica; e serão nomeadas pelos Presidentes em Conselho, aquelas mulheres, que sendo brasileiras e de reconhecida honestidade, se mostrarem com mais conhecimento nos exames feitos na forma do Art. $7^{\circ}$.

Art. 13. As Mestras vencerão os mesmos ordenados e gratificações concedidas aos Mestres. (BRASIL, 1878).

Embora essa Lei, em seu artigo 13, afirme que não haverá diferença entre o ordenado de mestres e mestras, ao excluir geometria da formação feminina automaticamente deixa menor o salário delas, pois quem ensinava essa disciplina tinha direito a nível maior de remuneração. A diferença curricular acarreta a diferença salarial e, por conseguinte, ainda reforça diversos valores sociais implícitos. Além disso, essa diferença curricular não se limita à disciplina de geometria, pois as meninas deveriam ter aulas de bordado e de culinária e, para as filhas das famílias ricas, de piano, francês.

Nesse primeiro momento, para ser uma mestra, segundo Louro (2000), era necessário ter uma moral inatacável e viver em um ambiente decente e saudável. Estes preceitos reforçam o perfil esperado para as educadoras da época e, ainda que a educação feminina pudesse ser uma forma de buscar a liberdade, ela veio representar, de fato, a extensão do lar.

A primeira educação dos filhos é reservada às mulheres, que, portanto, precisavam de melhor instrução para fazê-la. A elas é destinada a formação moral de suas crianças e, com isso, há também um aumento da responsabilidade por suas ações.

Fica evidente que a formação da mulher durante o período do Brasil Império (1822-1899) assumiu o papel de formação da esposa perfeita, segundo as normas religiosas difundidas pela Igreja Católica.

A maioria das mulheres no Império vivia em situação de dependência e inferioridade, com pequena possibilidade de instrução. Em algumas famílias mais abastadas, às vezes elas recebiam noções de leitura, mas se dedicavam sobretudo às prendas domésticas, à 
aprendizagem de boas maneiras e à formação moral e religiosa. O objetivo era sempre prepará-las para o casamento e, quando muito, procurava-se dar um "verniz" para o convívio social, daí o empenho em lhes ensinar piano e línguas estrangeiras, sobretudo o francês. (ARANHA, 2006, p. 229).

Com a chegada da família real e da corte portuguesa ao Brasil no final de 1807, muitos costumes foram mantidos, mas houve também influências significativas que acabaram transformando a situação reinante na colônia.

A partir da intensificação do processo de urbanização, o cotidiano da mulher pertencente à elite dominante no país começou a modificar-se. Para Saffioti (1976), ela deixou de ter a sua vida restrita à casa-grande. Passou a frequentar festas, teatros, ir à igreja e teve o seu círculo social aumentado. Contudo, sua instrução permaneceu desvalorizada, já que a expectativa social era de que ela fosse educada e não instruída.

Ademais, observamos também uma redefinição dos papéis entre os membros da família moderna. Houve uma aproximação das relações e a criança assumiu um lugar de destaque. A família se entrelaçava ao redor da criança e a mulher era incumbida da educação dos filhos e das atribuições da casa. Esta nova definição do papel da mulher na família foi desenvolvida tendo como base a maternidade.

É importante relatarmos que, apesar de a lei apresentar a possibilidade de instrução escolar para meninas, não havia escolas de formação para mulheres. Essas eram educadas em casa e, com a Lei Geral de 15 de outubro de 1927, que cria as escolas de primeiras letras no Brasil, é revelada a falta de professoras formadas e concursadas. Por meio da mesma lei, fica definido um salário menor para aqueles que não fossem concursados, logo, o salário das mulheres professoras nesse período era menor que o dos homens. A formação de professoras demora acontecer institucionalmente no Brasil, pois a primeira escola Normal (Escola de Niterói), criada em 1935, não recebia alunas, era uma escola masculina. Nesse aspecto, as instituições religiosas saem na frente e ofertam o curso Normal para meninas e assumem um papel importante na disseminação do imaginário social do que é ser professora primária no Brasil.

Além do discurso de valorização da mulher em decorrência do papel materno, outro aspecto importante está relacionado com o perfil do trabalhador brasileiro que se constituía. A formação de uma nova identidade do trabalhador 
brasileiro fazia parte do projeto de moralização da sociedade brasileira nas primeiras décadas do século XX. Estamos diante de um trabalhador dócil, submisso e economicamente produtivo. Para Rago (1985), havia a vontade de excluir a diferença, de normalização do outro. Nesta perspectiva, a família se tornou um elemento fundamental neste projeto e, a partir de então, se fez necessário disseminar um imaginário de mulher.

Durante a República Nova, na década de 1930, as mulheres ganharam um pouco de espaço no cenário político nacional ao receberem o direito ao voto, garantido pelo Código Eleitoral de 1932. No período compreendido entre as décadas de 1930 e 1969, embora tendo sido reconhecido por Getúlio Vargas seu direito ao voto, a expressão de movimentos de luta e contestação das mulheres era dificultada pelos ideais corporativistas do Estado Novo. Neste contexto, o entendimento do poder público era de que a educação deveria continuar a ser oferecida de modo diferenciado para os homens e as mulheres. "Assim, se o homem deve ser preparado com têmpera de teor militar para os negócios e as lutas, a educação feminina terá outra finalidade, que é o preparo para o lar” (SCHWARTZMAN; BOMENY; COSTA, 2000, p. 123).

Segundo Schwartzman, Bomeny e Costa (2000), a educação feminina era somente parte de um projeto mais amplo, integrando um plano mais audacioso que, com o argumento de oferecer proteção à família brasileira, tinha em suas raízes mais profundas a relação com a política de previdência social, com o papel da mulher na sociedade e com a política populacional do país.

Como exemplo deste plano podemos destacar o projeto de um decreto-lei intitulado "estatuto da família", que seria assinado por Vargas em 7 de setembro de 1939, elaborado pelo ministério de Capanema, mas que, em função de severas críticas de Francisco Campos e Oswaldo Aranha, não foi promulgado. Tal projeto reunia duas ideias essenciais: aumentar a população do país e consolidar e proteger a família em sua estrutura tradicional.

Este projeto de lei abordava questões próprias do núcleo familiar, mas também propunha medidas de repercussões mais pontuais. Como destaque, ele afirmava que, 
[...] o Estado adotaria medidas que restringissem a admissão de mulheres nos empregos públicos e privados, ou seja, não poderiam as mulheres ser admitidas senão nos empregos próprios da natureza feminina, e dentro dos limites restritos da convivência familiar. (SCHWARTZMAN; BOMENY; COSTA, 2000, p. 128).

A divisão de papéis e responsabilidades entre o homem e a mulher era destaque para a restrição ao trabalho feminino e também tinha impactos no campo educacional.

À mulher cabia ter características como a docilidade, a delicadeza, a fragilidade e a maternidade: "Ser mãe, esposa e dona de casa era considerado o destino natural das mulheres. Na ideologia dos Anos Dourados, maternidade, casamento e dedicação ao lar faziam parte da essência feminina; sem história, sem possibilidade de contestação” (BASSANEZI, 2006, p. 609).

Com o aumento da urbanização era perceptível o aumento gradativo do nível de escolaridade da população em geral, com destaque para as mulheres.

A educação escolar das mulheres passa a ser mais valorizada ao lado das concepções arraigadas de que as mulheres devem dedicar-se preferencialmente ao lar e aos filhos, fazendo com que o trabalho da mulher continue cercado de preconceitos e sendo visto como subsidiário ao do chefe de família. Muitas das distâncias entre homens e mulheres diminuem com as transformações urbanas: novas formas de lazer, novo pontos de encontro surgem nas cidades. Modificam-se regras e práticas sociais que vão do convívio nas ruas ao relacionamento familiar. (PINSKY, 2014, p. 28).

Por outro lado, ainda sobrevivem aspectos tradicionais das relações de gênero, como a separação de obrigações sociais com base no sexo, a valorização da castidade para a mulher e a moral sexual diferenciada para homens e mulheres.

A transformação nos modos e costumes concebida nos anos dourados proporcionou maior reflexão sobre o papel da mulher na sociedade e possibilitou uma diretriz para que o feminismo aos poucos se traduzisse em um movimento de maior força e representatividade. Apesar dos fortes impactos sociais da ditadura militar, as mulheres se organizavam e questionavam o papel historicamente construído no seio familiar e social. Os ideais de esquerda se uniram com os anseios de maior liberdade e participação social das mulheres e, com isso, houve uma maior abertura ao diálogo sobre as questões propostas pelo movimento feminista, como a busca por maior escolarização e a luta por melhores condições no mercado de trabalho. 
No rastro das reivindicações e conquistas femininas, movimentos emergentes, que tinham em sua agenda a superação das desigualdades e injustiças sociais, organizaramse em objetivos comuns, buscando principalmente retirar da invisibilidade segmentos sociais até então acobertados sob o manto da ignorância e do preconceito, em busca do reconhecimento e, por consequência, de um mundo mais humanizado. (ALMEIDA, 2004, p. 62).

Juntamente com a inserção feminina num espaço profissional representado pela educação na infância, há de se considerar que este cenário foi também o momento em que se dispersavam movimentos relacionados com diversas questões defendidas pelas mulheres, como as reivindicações de igualdade jurídica, direito a voto e acesso a instrução difundidos por mulheres do Reino Unido e dos Estados Unidos. Esses movimentos levaram a permissão do voto às mulheres a partir de 1918 no Reino Unido e em 1919 nos Estados Unidos.

Segundo Almeida (1998), neste cenário de conquistas sociais, as mulheres não foram estudar apenas para se prepararem para o casamento. A questão da feminização do magistério vai muito além do matrimônio, pois foi uma luta feminina na busca de independência e de liberdade dentro da sociedade.

\section{A formação das professoras alfabetizadoras em Minas Gerais}

Durante a análise dos trabalhos, encontramos apenas um homem atuando no ensino primário e, em apenas uma pesquisa sobre a Escola Normal, encontramos um homem que foi aluno. Conforme afirma Neves, "O curso Normal recebeu apenas mulheres, com exceção da turma matriculada no ano de 1952 que teve um aluno entre as doze alunas restantes" (NEVES, 2005, p. 149).

A ideia de que a mulher era a pessoa ideal para educar as crianças foi aos poucos sendo constituída socialmente, tendo a Igreja Católica como uma forte aliada e com uma função muito importante nesse processo. Ela foi a maior disseminadora dos cursos de formação de professores para mulheres por meio de internatos, semi-internatos e externatos.

As Escolas Normais eram a única possibilidade de estudo das mulheres durante um longo período, pois elas eram educadas para serem mães de família. "Por que você escolheu esse curso? Porque naquela época a mulher sempre 
caminhava pela área da Educação, ou você era casada ou você era professora ou as duas coisas ao mesmo tempo" (CARVALHO apud CUNHA, 2011, p. 153).

Nestes cursos era oferecida às alunas formação para atuar no ensino e, principalmente, para cuidarem de uma casa, dos filhos e do marido. Ser professora não era a primeira opção de formação para muitas estudantes. Algumas queriam fazer medicina, outras, engenharia. Contudo, seus pais só lhes permitiram realizar o curso Normal, e assim, para não ficarem somente em casa ou sem estudar, elas o cursavam, como podemos perceber na fala da alfabetizadora Resende (2014):

[...] era a proposta da época, para moça era mais a Escola Normal, não é? Aí a gente foi fazer a escola Normal, a opção que tinha aqui era a Escola Normal. Todo mundo fazia a Escola Normal e logo casava, e assim a gente fez.

Não, não... não tinha moço fazendo Curso Normal porque até então não usava na época, eles faziam mais opção por contabilidade.

A minha opção sempre foi de comércio, mas como não tinha outra opção, e também pai, naquela época, pai era muito assim, mandava muito assim nesse sentido e nós seguimos o que tinha. (RESENDE apud MORAES, 2014, p. 273).

Conforme Ferreira, o Colégio Normal de Patrocínio representava o ideal de ensino almejado pelos pais para suas filhas.

[...] o colégio tinha como objetivo formar a professora ideal. Segundo os dirigentes mineiros e, especialmente, os patrocinenses, a professora ideal era aquela que fosse abnegada, que encarasse a profissão como um sacerdócio, que possuísse uma sólida formação religiosa, que tivesse frequentado o Colégio Normal Nossa Senhora do Patrocínio, onde aprendera os métodos de ensino e os conhecimentos exigidos pela lei. (FERREIRA, 2006, p. 175).

Além disso, o Decreto $\mathrm{n}^{\circ}$ 2.836, de 31 de maio de 1910, restringe a frequência às escolas Normais ao sexo feminino. "Art. 2. As escolas normaes, sob a forma de externatos, serão freqüentadas exclusivamente por allumnas, às quaes será dada a educação intellectual, moral, physica e profissional, necessária ao preparo de professores primários com as qualidades indispensáveis ao magistério" (MINAS GERAIS, 1910, p. 152).

Desta forma, ao pensar na identidade dos alfabetizadores do período pesquisado, a realidade que encontramos é de que essa área de atuação era feminina, portanto constituída de alfabetizadoras. Tal fato corrobora o objetivo geral desta pesquisa, que foi analisar a formação de professoras da Escola Normal e do 
Magistério observando como o ensino feminino foi sendo socialmente idealizado como dom, bem como a relação entre a feminização e o exercício do magistério.

A Constituição do ser professor está permeada das concepções de moral, civismo e higiene. No período pesquisado, o Brasil viveu a política do Estado Novo, com Getúlio Vargas na presidência, e nele houve duas grandes reformas educacionais: a Reforma Francisco Campos e a Reforma Gustavo Capanema. Dessa última constaram a reforma do Ensino Primário e do Ensino Normal, que se refletiram diretamente na formação e na prática dos alfabetizadores.

As ideias difundidas nos colégios Normais construíram os saberes dessas professoras. Podemos perceber essa afirmação na fala de uma alfabetizadora que diz que o colégio foi muito importante para sua constituição:

O Colégio possuía, naquele tempo, um Manual de Boas Maneiras. Continha condutas e maneiras em todas as circunstâncias da vida, inclusive da vida política. Isso muito me ajuda hoje como atuante na vida política de minha cidade. Hoje não se fala em civilidade com pais, filhos, marido e esposa, patrões e empregados, alunos e professores. Nós tínhamos que decorar as regras de cortesia, de moral e até de passear, de fazer visitas. (PORTO apud FERREIRA, 2006, p. 210).

Depreendemos que o local de formação dessas professoras influenciou suas práticas e sua constituição como alfabetizadoras. O ideal de mulher que era apregoado nos cursos normais e no magistério refletiu na sua prática e na proporção numérica de mulheres atuando no magistério do ensino primário.

\section{As professoras alfabetizadoras nas teses e dissertações}

Nos trabalhos que analisamos há relatos e descrições de algumas normalistas, alfabetizadoras e professoras. Dentro do corpus de análise, encontramos algumas alfabetizadoras e apenas um alfabetizador. Dos 20 trabalhos, 8 utilizam a História Oral e disponibilizam as entrevistas, enquanto outros 7 usam as entrevistas como técnica.

A História Oral enquanto metodologia de pesquisa considera as entrevistas como fundamento da investigação e disponibiliza as entrevistas ou enxertos delas para compreensão das narrativas dos sujeitos entrevistados. Assim a História Oral valoriza as vivencias dos sujeitos entrevistados e da voz aos excluídos como afirma 
Thompson (1998). Sendo assim, apresentaremos a análise dos trabalhos que utilizaram a entrevista como metodologia (História Oral). Neles, identificamos 30 professoras alfabetizadoras e 1 professor alfabetizador, entre normalistas e professores, professores leigos e apenas normalistas como demonstra o gráfico a seguir (Figura 1).

Figura 1 - Normalistas e a docência segundo as teses e dissertações selecionadas

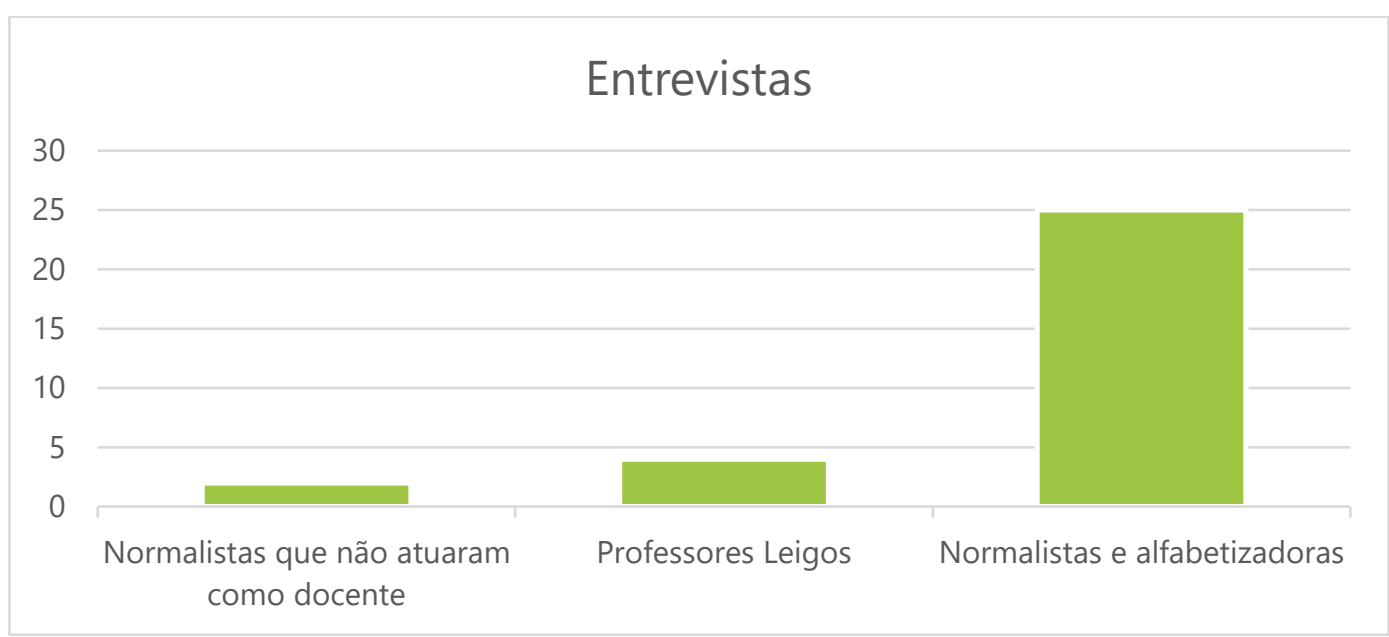

Fonte: Elaborada pelas autoras com os dados encontrados em 8 trabalhos de mestrado e doutorado.

Pelo gráfico constata-se que 25 normalistas se tornaram alfabetizadoras, o que significa que $80,64 \%$ das entrevistas encontradas nos trabalhos analisados são de alfabetizadoras, mas ele também nos revela que a normalista podia escolher outras áreas para atuar além da alfabetização. Apresentaremos a seguir quem são esses alfabetizadores e suas principais características de atuação pedagógica.

No estudo de Moraes (2008), História e Ofício de Alfabetizadoras: Ituiutaba 1931 1961 foram entrevistadas três alfabetizadoras: Saraiva, Machado e Pereira. Saraiva nasceu em 24 de fevereiro de 1919, na cidade de Monte Alegre - MG. Estudou na Escola Normal Dr. José Inácio, em Uberlândia, e atuou como alfabetizadora no período de 1937 a 1948. Realizou o curso para diretores na Escola de Aperfeiçoamento de Belo Horizonte.

Machado nasceu em 12 de julho de 1920 nas proximidades de Ituiutaba-MG, quando a cidade era denominada Vila Platina. Formou-se na primeira turma de normalistas do Instituto Mardenl. Atuou como alfabetizadora por 36 anos, 
aposentou-se em 1972 e, mesmo após o encerramento das atividades como alfabetizadora, foi Diretora do Centro Espírita Eurípedes Barsanulfo.

Pereira nasceu em 15 de abril de 1938 em Ituiutaba. Foi professora leiga e atuou como alfabetizadora desde 1952. No início de suas atividades atuou como professora particular nas fazendas e depois em escola da zona rural. Aposentou-se em 1979, mas ainda teve participação efetiva na Paróquia de Nossa Senhora da Abadia.

Na pesquisa realizada por Martins (2010), intitulada Ser professora na República: Modos de pensar, sentir e agir (1930-1950), deparamos com 4 alfabetizadoras: Freitas, Pereira, Carrijo e Antonialli. Freitas nasceu em 16 de abril de 1921 em Ituiutaba-MG e cursou o ensino primário na década de 1930 no Grupo Escolar da mesma cidade, sendo, depois, aluna interna na Escola Normal Prof. José Inácio de Souza em Uberlândia-MG. Concluiu o ensino normal por volta de 1937 e atuou como professora primária em Frutal-MG no período de 1938 a 1941. Em 1942, foi para Uberlândia, sendo nomeada para atuar como professora primária no Grupo Escolar Júlio Bueno Brandão. $\mathrm{Na}$ data da entrevista, estava aposentada e solteira. Freitas afirmou que sempre quis ser professora.

Pereira nasceu em 22 de setembro de 1916 em Uberlândia-MG. Em 2008, estava aposentada e tinha 92 anos. Ela cursou o Ensino Normal na Escola Normal Prof. José Inácio de Sousa e o concluiu em 1933. Atuou 27 anos como professora, mas a maior parte do tempo trabalhou com a $3^{\mathrm{a}}$ e $4^{\mathrm{a}}$ séries. Segundo Pereira, ela preferia essas turmas e sempre sonhou em ser professora.

Carrijo nasceu na Fazenda da Tenda, distrito de Uberlândia-MG, no dia 05 de junho de 1920. Estudou o primário na Fazenda da Tenda e, depois, estudou por conta própria e com professores particulares. Por volta de 1944, fez o ginasial de três anos em um ano. Cursou o Normal na década de 1950 na Escola Normal Prof. José Inácio de Sousa.

Antonialli nasceu em Santa Rita do Paranaíba, hoje Itumbiara-GO, em 15 de abril de 1927. Em 2008, tinha 81 anos e ainda trabalhava como professora de pintura em telas. Cursou o ginasial em São Paulo, em um colégio interno, e o Normal na Escola Normal Prof. José Inácio de Sousa em Uberlândia-MG. Carrijo relata a falta de uma faculdade na cidade de Uberlândia, o que restringiu as 
possibilidades de formação para as mulheres. Com estas dificuldades, o magistério era a profissão mais procurada.

$\mathrm{Na}$ dissertação Histórias de Alfabetizadores: Vida, Memória e Profissão, de Guimarães (2006), foram entrevistados quatro alfabetizadores. É importante mencionarmos que esse foi o único trabalho em que encontramos um homem atuando como alfabetizador. Os alfabetizadores apresentados no trabalho são: Fernandes, Silva, Vieira e Gonçalves.

Fernandes nasceu em Patos de Minas em 1953. No período da pesquisa era casada e tinha dois filhos. Foi alfabetizada de maneira informal. Segundo a entrevistada, ela acompanhava as aulas de uma escola próxima à sua casa e assim foi alfabetizada. Fez o Curso Normal, posteriormente um curso superior, habilitando-se em Administração, e um curso de Pós-graduação Lato Sensu com ênfase em Alfabetização.

Silva é o único homem que encontramos nos trabalhos pesquisados. Ele nasceu no meio rural, na localidade Mata do Brejo, município de Patos de Minas, em 1922. Trabalhou como alfabetizador por 30 anos. Sua alfabetização se iniciou aos 8 anos e prosseguiu até os 12 , sempre em escolas particulares. Começou a trabalhar na prefeitura em 10 de agosto de 1959 como professor alfabetizador, na localidade de Mata do Brejo, possuindo como formação apenas o ensino primário. O alfabetizador cursou o Magistério do segundo grau na modalidade de ensino supletivo no ano de 1983, final da sua carreira.

Vieira nasceu na cidade de Patos de Minas em 1945 e sua formação básica foi o Curso Colegial Normal. Apesar de ter prestado vestibular duas vezes, não fez um curso superior, pois casou-se, teve filhos e ainda lecionava em dois períodos, o que inviabilizou a realização de seu projeto. É relevante relatarmos que Vieira foi alfabetizada pelo método global de contos. Ela atuou por 32 anos como alfabetizadora e, após aposentar-se na rede pública, foi atuar como alfabetizadora na rede particular, local em que se aposentou.

Gonçalves nasceu na zona rural de Patos de Minas, na localidade Serra de Queiroz, em 1951. Tinha 9 irmãos e, para estudar, teve que vir morar na cidade trabalhando durante o dia e estudando à noite. Segundo ela, lecionar era um sonho de infância. Começou a lecionar tendo cursado apenas a $\sigma^{\mathrm{a}}$ série e somente realizou a formação básica para o exercício do magistério por meio do ensino supletivo. 
"Concluímos o $2^{\circ}$ grau no ensino supletivo, Projeto Lume, que corresponde ao CESU, ele é inscrito em Goiás" (GONÇALVES apud GUIMARAES, 2006, p. 127). Gonçalves alfabetizou por 26 anos e, após a aposentadoria, tornou-se comerciante.

No estudo Modos de Alfabetizar no Grupo Escolar Clarimundo Carneiro - 1963 a 1973, de Lepick (2013), foram entrevistadas cinco pessoas, sendo uma delas a diretora do Grupo Escolar Clarimundo Carneiro. Apresentaremos apenas as alfabetizadoras Silva, Fernandes, Lobato e Ferreira, excluindo a professora que atuava na direção da escola.

Silva, nascida na zona rural de Uberlândia, no dia 06 de novembro de 1922, realizou o Curso Normal na Escola Prof. José Inácio de Sousa em 1944 e começou a lecionar em 1947. A docência foi uma escolha de infância. É viúva e aposentada e, no período da entrevista, morava com uma moça que considerava como filha.

Fernandes nasceu no dia 11 de agosto de 1938 em Martinésia, distrito de Uberlândia. Na época da entrevista era viúva e tinha uma das pernas amputadas. Apesar das dificuldades de locomoção, Fernandes continuou como uma pessoa ativa após a aposentadoria. Atuou como alfabetizadora até se aposentar em um dos cargos há aproximadamente 30 anos, pois tinha dois cargos. Segundo Fernandes, ela começou a lecionar sem formação específica para tal.

Fernandes cursou o Normal na Escola Brasil Central e posteriormente, no período noturno, a faculdade de Supervisão na Associação Brasil Central de Educação e Cultura.

Lobato nasceu em Uberlândia no dia 26 de novembro de 1942 e foi alfabetizada pelo seu pai pela Cartilha da Infância antes de ir para escola. Depois estudou desde o jardim de infância até o Curso Normal no Colégio Nossa Senhora das Lágrimas. Era bolsista, pois sua família não tinha recursos para custear as mensalidades. Lobato não se casou e aposentou-se em 1992, mas continuou na ativa ministrando palestras e cursos.

Ferreira nasceu no dia 13 de julho de 1943 em Uberlândia e foi alfabetizada pelo seu pai, pois morava na fazenda. Ela mudou-se para a cidade e ficou morando com sua avó. Estudou no Externato São José e depois cursou o Normal no Colégio Nossa Senhora das Lágrimas. No ano seguinte, após ter-se formado, começou a trabalhar. Atuou como alfabetizadora de 1965 a 1970. 
Cunha (2011), em sua tese intitulada História da Alfabetização de Ituiutaba: vivências no Grupo Escolar Governador Clóvis Salgado - 1957-1971, apresenta cinco entrevistas, quatro das quais com alfabetizadoras que atuaram no referido Grupo no período pesquisado.

Diniz foi aluna do Grupo Escolar Governador Clóvis Salgado e foi alfabetizada em 1966 pelo método Global de Contos. Formou-se em Letras e atuou como alfabetizadora em outro colégio. Como alfabetizadora, utilizou o livro Barquinho Amarelo, escolhido pela escola, que seguia o método Global.

Carvalho atuou 17 anos como educadora no Grupo Escolar Clóvis e no Lion. Entre 1957 e 1968 lecionou no Grupo Escolar Clóvis Salgado Filho. Foi alfabetizada de 1944 a 1945 pela Cartilha da Infância e formou-se em 1956 no Instituto Marden. No período em que atuou como alfabetizadora, utilizou a cartilha da Infância e a cartilha Analítica. Segundo Carvalho, ela não trabalhou com o método Global, mas "tinha outra professora que trabalhava" (CARVALHO apud CUNHA, 2011, p. 150).

Moraes atuou como alfabetizadora por 11 anos na escola Clóvis Salgado. Foi alfabetizada pelo método silábico e fez o curso Normal em Belo Horizonte na escola Isabela Hendrix, que era americana. Ali, onde havia uma escola de aplicação, foi-lhe ensinado o método Global. Moraes foi a primeira pessoa a trabalhar com esse método em Ituiutaba, apresentando-o para as professoras daquela cidade.

Signorelli foi aluna do Grupo Escolar Governador Clóvis Salgado e foi alfabetizada em 1962 pela Professora Nanci, pelo método silábico. Signorelli fez o curso normal no Instituto Marden, em 1970, à época intitulado Colégio Normal Benedito Valadares. Além disso, cursou Pedagogia e fez a complementação em Orientação Educacional. Foi alfabetizadora durante 7 anos e utilizou o método fônico. Ela trabalhou na escola Professor Álvaro Brandão de Andrade e no Rotary, sendo que, na última escola, atuou de 1972 a 1980.

$\mathrm{Na}$ investigação História de alfabetizadoras uberlandenses: Modos de fazer no Grupo Escolar Bom Jesus - 1955 a 1971, realizada pela pesquisadora Lima (2011), há narrativas de cinco alfabetizadoras que atuaram no referido Grupo no período da pesquisa. São elas: Pafume, Aguiar, Zacarias, Bezerra e Mancini. 
Pafume, aposentada, viúva e mãe de três filhos, nasceu em 05 de janeiro de 1931. Cursou o Normal no Colégio Nossa Senhora das Lágrimas em Uberlândia. Relatou que queria ser médica, mas, como não havia o curso em Uberlândia e seu pai não a deixou fazer o curso de medicina em outra localidade, a única opção que existia naquele momento era o curso Normal. Pafume afirma que "gostou muito do curso Normal e se sente realizada na profissão que exerce e completou dizendo que nunca vai permanecer estagnada" (PAFUME apud LIMA, 2011, p. 93). Ela foi alfabetizada no colégio Brasil Central pelo método alfabético. Trabalhou por trinta anos com educação, dez dos quais com turmas de alfabetização.

Aguiar, nascida em 18 de setembro de 1946, cursou o Normal no Colégio Nossa Senhora das Lágrimas e, depois de um intervalo, cursou Pedagogia na Faculdade de Uberaba. Começou a atuar na alfabetização em 1964 e nela permaneceu durante 11 anos, depois atuou de forma indireta. Esta alfabetizadora trabalhou com cartilhas do método eclético e com o método Global.

Zacarias nasceu em 29 de maio de 1937 e atualmente é aposentada, viúva, mãe de três filhas. Foi alfabetizada pela sua mãe, observando-a ensinar a irmã mais velha. "E quando a mamãe ensinava para minha irmã mais velha, eu ficava assim, atrás das duas, para ver. E foi assim que aprendi a ler" (ZACARIAS apud LIMA 2011, p. 151). Segundo Zacarias, ela realizou o curso Normal no Colégio Nossa Senhora das Lágrimas e, embora quisesse mesmo estudar artes e música, em obediência ao seu pai cursou o Normal. Trabalhou por quatro anos nas salas de alfabetização e utilizou o método Global.

Bezerra nasceu em 22 de maio de 1939, é aposentada, divorciada e tem um casal de filhos. Cursou o Normal no Colégio Nossa Senhora das Lágrimas e, depois, Pedagogia. Atuou nas salas de alfabetização durante 25 anos. Bezerra iniciou o seu processo de alfabetização informalmente com seu pai e depois frequentou a escola Adventista em Várzea Grande, onde foi alfabetizada com a cartilha Sodré. Segundo a alfabetizadora, ela utilizou as cartilhas do método eclético e do método Global com seus alunos.

Mancini, casada, aposentada, nasceu em 01 de julho de 1948 e cursou o Normal no Colégio Imaculada Conceição em Tupaciguara. Ela relata que sempre gostou de dar aula: "Toda vida eu pensei que daria aula. E sempre gostei do 
primário, das salas das primeiras séries” (MANCINI apud LIMA, 2011, p. 162). Importante relatarmos que Mancini foi alfabetizada pelo método silábico. Como alfabetizadora, ela utilizava a cartilha Caminho Suave para fazer o preparatório dos alunos e depois outra do método Global.

$\mathrm{Na}$ tese de doutorado intitulada História e Memória da Formação Docente em Ituiutaba-MG, de Moraes (2014), há 10 entrevistas de ex-alunas, ex-professoras e ex-diretor de Escolas Normais de Ituiutaba. Nessas dez narrativas, conseguimos identificar um diretor escolar e 9 normalistas, das quais 7 foram professoras alfabetizadoras. As normalistas foram: Ester Majadas Araújo, Celeida Alves de Moraes Ribeiro, Geórgia Marai Finholdt Ribeiro, Helena Theresa de Moura Carvalho, Maria Terezinha Pereira Resende, Maria Mirza Cury Diniz e Vera Cruz de Oliveira Moraes.

Araújo atuou como monitora nas salas de alfabetização e posteriormente em outras turmas. Iniciou sua carreira docente aos 13 anos. Concluiu o curso Normal no Instituto Marden em 1940. Foi professora no curso Normal. Já Ribeiro atuou em 1953 no ensino primário na cidade de Canápolis e, em 1973, no Instituto Marden. Concluiu o Curso Normal na primeira turma do Colégio Normal Municipal em 1969. Atuou como docente no curso Normal da Escola Municipal Machado de Assis.

Finholdt atuou como professora no Instituto Marden, porém iniciou sua carreira docente aos 12 anos como monitora e depois cursou o Normal na Escola Normal do Instituto Marden. Trabalhou com diferentes turmas do ensino primário e, durante o curso Normal, nas salas de educação de adultos.

Carvalho atuou como alfabetizadora de adultos e como docente no Grupo Escolar de Ituiutaba. Cursou o Normal na Escola Normal do Colégio Santa Teresa em 1957, tendo sido aluna da primeira turma dessa escola. Resende atuou como alfabetizadora e, em sua entrevista, relata que utilizou o método Global para alfabetizar seus alunos. Em 1969 concluiu o Ensino Normal na Escola Normal Colégio São José em Ituiutaba. Atuou na Escola Coronel Tonico Franco, na E. E. Governador Bias Fortes e na E. E. Álvaro Brandão, onde se aposentou.

Diniz iniciou a docência aos 13 anos na cidade de Gurinhatã em uma turma multisseriada do ensino primário com 60 alunos. Ela afirma que não foi sua escolha fazer o curso Normal, que gostaria de cursar medicina, mas, como em Ituiutaba só 
havia o curso Normal, ela o fez na Escola Normal do Instituto Marden e o concluiu em 1951. Depois, já na década de 1970, formou-se em Pedagogia. Atuou como docente nas séries iniciais no Instituto Marden e como alfabetizadora na E. E. Cônego Ângelo. Vera Cruz de Oliveira Moraes concluiu em 1961, no Instituto Marden, o Curso Normal e, posteriormente, cursou Pedagogia na Faculdade Educacional de Ituiutaba.

A partir das análises, constatamos que 56\% das normalistas realizaram o curso Normal em escolas confessionais e 44\% em escolas consideradas laicas. Porém, na análise dos trabalhos, podemos identificar um traço religioso na fala de todas as normalistas, o que se justifica em parte pelo Decreto-Lei $n^{\circ} 8.530$ de 1946: “Art. 15. O ensino religioso poderá ser contemplado como disciplina dos cursos de primeiro e segundo ciclos do ensino normal, não podendo constituir, porém, objeto de obrigação de mestres ou professores, nem de frequência compulsória por parte dos alunos" (BRASIL, 1946).

Como vivíamos um momento em que a religião ainda influenciava a formação dos professores, quando o decreto afirma que "a educação moral e cívica não deverá constar de programa específico, mas resultará do espírito e da execução de todo o ensino", acaba por deixar escrito em lei como a moral deve perpassar todas as disciplinas. Nessa pesquisa compreendemos que a moral difundida nas escolas Normais era pautada nos princípios religiosos e na definição de um papel para a mulher na sociedade. A influência desse ideário difundido nas Escolas normais foi além das práticas das alfabetizadoras, refletindo na vida e no papel social que essas mulheres assumiram nas sociedades que estavam inseridas. A escola preconizou modelos de civilidade, e uma concepção de mulher, mãe e esposa que refletiu diretamente na constituição social das normalistas para além da escola.

\section{Considerações finais}

Com a pesquisa, evidenciamos que a escolha das professoras pelo magistério não foi sempre motivada pelo desejo ou sonho pela profissão. As normalistas / professoras alfabetizadoras eram para ela direcionadas em decorrência de elementos relacionados ao contexto familiar, principalmente a vontade dos pais, a falta de 
condições financeiras e a força da imposição moral vigente a partir dos valores cristãos disseminados nas Igrejas.

Nas entrevistas de algumas professoras, a justificativa da escolha profissional a partir de certo "dom”, aliado à imposição dos pais, revelou indícios e pormenores de que havia um conteúdo velado a ser observado com maior cautela.

Para Almeida (1998), esse processo de feminização do magistério se deu em função das mudanças sociais que levaram a mulher a pensar e lutar por sua liberdade. Assim, o magistério era, para ela, a opção mais próxima dessa liberdade financeira e intelectual. Portanto, os Cursos Normais não eram apenas lugares para esperar o casamento, mas, sim, um lugar de profissionalização e libertação feminina. No entanto, ao analisar os trabalhos, identificamos que 90\% das professoras alfabetizadoras / alunas normalistas esperavam casar-se depois de concluir o curso, outras chegaram a abandonar o curso Normal para se casar e algumas terminavam o curso e não trabalhavam porque se casariam. Esse discurso de formar uma mulher ideal para a sociedade foi difundido pelas escolas normais confessionais, assim como pela Igreja Católica, que, diante do movimento renovador, se aproximou da sociedade no intuito de manter a ordem estabelecida.

Nos trabalhos analisados observamos que as Escolas Normais foram redutos de formação de mulheres segundo os preceitos morais católicos, que pregavam a importância da submissão feminina, a doçura da mulher, a paciência e a fragilidade como valores importantes para a criação e a educação religiosa de seus filhos.

A formação das normalistas no período de 1946-1979 se confundia com o papel da mãe e, a partir de então, emergia a ideia de vocação e de que o magistério primário era uma função maternal que se transferia dos filhos para os alunos. $\mathrm{O}$ entrelaçamento dos conceitos de mãe, mulher e professora partia de uma construção social em que esta mulher-mãe-professora é iluminada para o saber e a moralidade, destinada a cuidar das frágeis crianças, a orientá-las e transformá-las pela capacidade natural de disseminarem seu dom, sua vocação. Tal encadeamento pode ser observado na fala de uma professora: "Desde menina eu queria ser professora. Desde menina eu tinha vocação para ser professora" (SILVA apud LEPICK, 2013, p. 74).

As narrativas apresentadas pelas alfabetizadoras retratam um aspecto da realidade do período pesquisado, abordando diversos elementos para a escolha de 
sua profissão. Entre eles há de se destacar a falta de opções que elas enfrentavam ao tomar esta decisão. Por ser mulher, os pais não as deixavam estudar em outra cidade, por isso procuravam as Escolas Normais, única possibilidade profissionalizante existente onde moravam, que formavam mulheres para $\mathrm{O}$ magistério. Segundo Antonialli (apud MARTINS, 2009, p. 158), "Com a convivência que eu tinha, busquei uma profissão que era mais indicada na época. [...] $\mathrm{Na}$ época, a maioria das mulheres era encaminhada para serem professoras, não tinha faculdade na região".

Na verdade, a minha paixão naquela época era fazer medicina, eu queria medicina de qualquer jeito. Mas como fazer? Sou de uma família numerosa, uma família de seis homens e três mulheres. Uma família árabe que achava que os homens tinham que fazer, meu pai tinha uma meta na vida. E ele cumpriu. Que todos os filhos dele fariam curso superior. [...]. (DINIZ apud MORAES, 2014, p. 282).

Muitas professoras queriam fazer outros cursos e seguir carreiras diferentes do magistério. Algumas, desde a infância, já foram direcionadas para o ensino. Muitas professoras foram em busca da profissão que era mais aceitável diante dos anseios sociais.

Para as mulheres das classes médias e dominantes, casar-se era a forma, respectivamente, de ascender na escala social ou manter a mesma posição em caso de infortúnio, mesmo que não amassem o futuro marido. Se o casamento fosse difícil de conseguir, precisavam, essas moças, para não serem um peso para a sociedade ou terem de viver da caridade alheia, obter um meio de sobrevivência proporcionado por uma profissão digna, de acordo com o ideal feminino e que não atentasse contra os costumes herdados dos portugueses de manter a mulher no espaço doméstico e no cuidado com as crianças. (ALMEIDA, 1998, p. 62).

O exercício do magistério representava, desta forma, um prolongamento das funções maternas de cuidado com os filhos e instruir e educar crianças era considerado aceitável para as mulheres. A docência era uma profissão digna e honrada para as mulheres exercerem, conforme destaca uma alfabetizadora:

A minha mãe me estimulou muito a ser professora. Interessante, Andreia, é [...] o professor, ele era muito respeitado. Muito acatado. Mesmo eu muito nova, eles tinham uma honra, assim um respeito pela minha pessoa. [...] Os professores tinham um verdadeiro status naquela época, quando eu era professora. (DINIZ apud MORAES, 2014, p. 283). 
$\mathrm{Na}$ fala das alfabetizadoras observamos um reflexo do discurso hegemônico que associa a docência primária aos atributos considerados femininos, colocando-a como um dom feminino, já que para exercê-la era essencial ter renúncia, delicadeza, amor às crianças, o que se relaciona intrinsecamente com a maternidade, estando em consonância com Louro (1997), Lopes (1991) e Chamon (2006). A proposta desenvolvida era de uma escola que formasse o professor a partir dos preceitos de caráter, moral e higiene difundidos pela igreja e pelas elites brasileiras.

Apesar de todas as características da formação das professoras alfabetizadoras, não podemos limitar o papel exercido por elas à mera extensão da vida doméstica. Muitas normalistas conseguiram, após algum tempo, seguir outras carreiras, como uma delas que se engajou na vida política de Patrocínio-MG, e outras que, de forma discreta, tentaram ocupar um lugar de igualdade de gênero na sociedade sexista nas décadas de 1940 a 1970.

\section{Referências}

ALMEIDA, J. S. Mulher e Educação: a Paixão pelo Possível. São Paulo: UNESP, 1998.

ALMEIDA, J. S. Mulheres na Educação: Missão, vocação e destino? In: SAVIANI, D. et al. (org.). O legado educacional do século XX no Brasil. Campinas, SP: Autores Associados, 2004.

ARANHA, M. L. A. História da Educaşão e da Pedagogia Geral e do Brasil. 3. ed. São Paulo: Moderna, 2006.

BASSANEZI, C. Mulheres dos anos Dourados. In: DEL PRIORE, M. (org.); BASSANEZI, C (coord. de textos). História das Mulheres no Brasil. São Paulo: Contexto/Ed. UNESP, 2006. p. 607 - 639.

BRASIL. Lei de 15 de outubro de 1827. Manda criar escolas de primeiras letras em todas as cidades, vilas e lugares mais populosos do Império. In: Coleção das Leis do Império do Brasil de 1827 - primeira parte. Rio de Janeiro: Tipografia Nacional, 1878. p. 71-73.

BRASIL. Decreto-Lei $n^{\circ} 8.530$ de 2 de janeiro de 1946. Lei Orgânica do Ensino Normal. Disponível em: <http://www2.camara.leg.br/legin/fed/declei/1940-1949/decreto-lei8530-2-janeiro-1946-458443-publicacaooriginal-1-pe.html> Acesso em: 26 nov. 2015.

BRASIL. Ministério da Educação e Saúde. Decreto-lei 8.347, de 10 de dezembro de 1945. Dá nova redação aos arts. 5, 15, 19, 20, 24, 25, 28, 35, 36, 38, 39, 43, 45, 49, 50, 51, 85, 88 e 91 do Decreto-Lei n.4.244, de 9 de abril de 1942. Diário Oficial da União, Brasília, Seção 1, 13 dez. 1945. p. 18616. (Publicação Original). Disponível em: < https://www2.camara.leg.br/legin/fed/declei/1940-1949/decreto-lei-8347-10-dezembro1945-416352-norma-pe.htmlt.> 
BURKE, P. (org.). A Escrita da História: novas perspectivas. Trad. Magda Lopes. São Paulo: Editora UNESP, 1992.

CARVALHO, M. P. Trabalho docente e as relações de gênero. Revista Brasileira de Educação. São Paulo, v. 1, n. 2, p. 77-84, maio/ago. 1996.

CHAMON, M. Trajetória de feminização do magistério e a (con)formação das identidades profissionais. In: SEMINÁRIO DE REDESTRADO - REGULAÇÃO EDUCACIONAL E TRABALHO DOCENTE, 7., 2006, Rio de Janeiro. Anais... Belo Horizonte: UFMG, 2006. Disponível em: <www.fae.ufmg.br/estrado/cd_viseminario/.../eixo.../trajetoria_de_feminizacao.doc> Acesso em: 20 mar. 2016.

CUNHA, T. R. S. História da alfabetização de Ituiutaba: vivências no Grupo Escolar Governador Clóvis Salgado-1957-1971. 164 f. Tese (Doutorado em Educação) Faculdade de Educação, Universidade Federal de Uberlândia, Uberlândia, 2011.

FERREIRA, H. O. Colégio Normal Nossa Senhora do Patrocínio: um instrumento de educação feminina na Zona do Alto Paranaíba em Minas Gerais/ 1928-1950. Tese (Doutorado em História) - Faculdade de História, Direito e Serviço Social - Universidade Estadual Paulista "Júlio de Mesquita Filho", Franca, 2006.

FERREIRO, E.; TEBEROSKY, A. Psicogênese da lingua escrita. Porto Alegre: Artes Médicas, 1991.

GUIMARÃES, E. G. A. Histórias de alfabetizadores: vida, memória e profissão. Dissertação (Mestrado em Educação) - Faculdade de Educação, Universidade Federal de Uberlândia, Uberlândia, 2006.

LEPICK, V. Modos de alfabetizar no grupo escolar Clarimundo Carneiro - 1963 a 1973.2013267 f. Dissertação (Mestrado em Educação) — Faculdade de Educação, Universidade Federal de Uberlândia, Uberlândia, 2013.

LIMA, M. C. História de alfabetizadoras uberlandenses: modos de fazer no Grupo Escolar Bom Jesus1955 a 1971. Dissertação (Mestrado em Educação) — Faculdade de Educação, Universidade Federal de Uberlândia, Uberlândia, 2011.

LOPES, E. M. T. A Educação da mulher: a feminização do magistério. Teoria \& Educação. Rio Claro, v. 4, p. 22-40, 1991.

LOURO, G. L. Gênero, sexualidade e educação. Uma perspectiva pós-estruturalista. Petrópolis, RJ: Vozes, 1997.

LOURO, G. L. Mulheres na sala de aula. In: DEL PRIORE, M. (org.); BASSANEZI, C. (coord. de textos). História das Mulheres no Brasil. São Paulo: Contexto/Ed. UNESP, 2000. p. 443-481.

MARTINS, R. M. S. Ser professora na república: modos de pensar, sentir e agir (1930-1950). Dissertação (Mestrado em Educação) — Faculdade de Educação, Universidade Federal de Uberlândia, Uberlândia, 2010.

MINAS GERAIS. Secretaria de Estado dos Negócios do Interior. Decreto n 2836 de 31 de maio de 1910. Aprova o Regulamento que reorganiza as escolas 
normaes do Estado. Belo Horizonte, 2016. Disponível em: $<$ https://repositorio.ufsc.br/handle/123456789/122290> Aceso em 12 jan.

MORAES, A.D. J. História e oficio de alfabetizadoras: Ituiutaba 1931 - 1961. 2008. Dissertação (Mestrado em Educação) - Faculdade de Educação, Universidade Federal de Uberlândia, Uberlândia, 2008.

MORAES, A. D. J. História e Memória da Formação Docente em Ituiutaba - MG. Tese (Doutorado em Educação) — Faculdade de Educação, Universidade Federal de Uberlândia, Uberlândia, 2014.

NEVES, G. T. A. A educação feminina no projeto siqueirano: 1939-1973. 2005. 209 f. Dissertação (Mestrado em Educação) — Universidade Federal de Uberlândia, Uberlândia, 2005.

PINSKY, C. B. Mulheres dos Anos Dourados. São Paulo: Contexto, 2014.

RAGO, M. Do cabaré ao lar: a utopia da cidade disciplinar. Brasil 1890-1930. Rio de Janeiro: Editora Paz e Terra, 1985.

SAFFIOTI, H. I. B. A mulher na sociedade de classes: mito e realidade. São Paulo: Quatro Artes - INL, 1976.

SCHWARTZMAN, S.; BOMENY, H. M. B.; COSTA, V. M. R. Tempos de Capanema. 2. ed. São Paulo; Rio de Janeiro: Paz e Terra, Editora da Fundação Getúlio Vargas, 2000.

THOMPSON, P. A voz do passado, história oral. São Paulo: Paz e Terra, 1998.

RECEBIDO: $31 / 08 / 2020$

APROVADO: 06/10/2020

RECEIVED: 08/31/2020

APPROVED: $10 / 06 / 2020$

RECIBIDO: $31 / 08 / 2020$

APROBADO: 06/10/2020 